\title{
Representaciones del animal que orina
}

\author{
José Antonio Colón Fraile \\ Universidad de Málaga \\ colonfrailealbaida@hotmail.com
}

RESUMEN: Durante siglos el papel de los animales en la gran Historia del Arte ha sido secundario, apareciendo generalmente de comparsa del ser humano, acompañándole en su trabajo o en la intimidad doméstica de sus hogares, aunque, a pesar de ese papel secundario, siempre hayan estado presentes. Desde las cuevas del Paleolítico hasta la posmodernidad, los artistas han representado a los animales enfatizando cualidades como su ferocidad, su naturaleza salvaje, su belleza anatómica, lo anecdótico de sus comportamientos, o su porte y nobleza. Se han establecidos muchas clasificaciones de animales en los estudios artísticos, dividiéndolos entre domésticos o salvajes, reales o fantásticos, motivo único o acompañamiento, etc. Añadimos un primer requisito poco convencional a estas clasificaciones, que será la condición de que aparezcan representados en el momento de orinar. El muestrario no es amplio, pero sí significativo desde el punto de vista iconográfico.

PALABRAS CLAVE: Animales; Orina; Iconografía.

\section{Pissing Animals Representations}

ABSTRACT: For centuries the role of animals in the great History of Art has been secondary, generally appearing as an ally of the human being, accompanying him in his work or in the domestic intimacy of their homes, although, in spite of that secondary role, they have always been present. From the Paleolithic caves to postmodernity, artists have represented animals emphasizing qualities such as their ferocity, their wild nature, their anatomical beauty, the anecdotal of their behavior, or their bearing and nobility. Many classifications of animals have been established in artistic studies, dividing them into domestic or wild, real or fantastic, unique motive or accompaniment, etc. We add a first unconventional requirement to these classifications, which will be the condition that they appear represented at the time of urination. The sample is not a large one, but it is significant from an iconographic point of view.

KEYWORDS: Animals; Urine; Iconography.

Recibido: 25 de febrero de 2019 / Aceptado: 7 de mayo de 2019.

\section{Introducción}

Animal y hombre son categorías paralelas, en tanto que ambos arrancan de un orden evolutivo en el que compartieron estadios comunes en un principio y, aunque la evolución los llevó por senderos distintos «resulta imposible prescindir, en un pequeño o gran espacio, de esa complementariedad, casi permanente, importante, vital a veces, entre los animales y los hombres» (Muñoz, 1984: 9). Esta complementariedad, la mayoría de las veces manifestada en un sometimiento jerárquico del animal, es evidente a lo largo de la historia, utilizándolos el hombre «según las ocasiones, como alimento, fuerza de trabajo, diversión o compañía» (Morgado y Rodríguez, 2011: 10).

Fruto de esta relación secular es también el deseo del hombre de reproducir las formas de los animales, de representarlos en el Arte. Pero esa representación, a la par que establece un vínculo entre el animal representado y el hombre que lo representa (Muñoz, 1984: 13), proyecta también una particular visión que el ser humano tiene de la naturaleza, que es en

Cómo citar este artículo: COLÓN FRAILE, José Antonio, «Representaciones del animal que orina», Boletín de Arte-UMA, n. 40 , Departamento de Historia del Arte, Universidad de Málaga, 2019, pp. 99-113, ISSN: 0211-8483, e-ISSN: 2695-415X, DOI: http://dx.doi.org/10.24310/BoLArte.2019.v0i40.5676 
definitiva un producto cultural que cambia y evoluciona a lo largo del tiempo y como tal se convierte en objeto de estudio científico y académico (Morgado y Rodríguez, 2011: 10).

Durante siglos el papel de los animales en la gran Historia del Arte fue secundario, apareciendo generalmente de comparsa del ser humano, acompañándole en su trabajo o en la intimidad doméstica de sus hogares, aunque, a pesar de ese papel secundario, siempre estuvieron presentes. Desde las cuevas del Paleolítico hasta la posmodernidad, los artistas han representado a los animales enfatizando cualidades como su ferocidad, su naturaleza salvaje, su belleza anatómica, lo anecdótico de sus comportamientos o su porte y nobleza.

Al trabajo de zoólogos, naturalistas, etnólogos, antropólogos y literatos, se unió también el de los artistas denominados «animalistas», aquellos que han cultivado de manera amplia la representación de animales en su producción artística, como sujetos de pinturas, dibujos y grabados (Mezzalira, 2013: 23) e historiadores, que ayudaron a elevar el estatus de la representación del animal, ocupando hoy en día una parcela específica de estudio dentro de la Historia del Arte. El auge de los Animal Studies en las últimas décadas es la manifestación de un interés que se engloba dentro de una mayor sensibilización global hacia «cuestiones medioambientales» (Morgado y Rodríguez, 2011: 5) propia de nuestra sociedad actual.

Se han establecidos muchas clasificaciones de animales en los estudios artísticos, dividiéndolos entre domésticos o salvajes, reales o fantásticos, motivo único o acompañamiento, etc. Estas clasificaciones se hacen, desde época aristotélica, con un afán de parcelación del saber y dependen de los valores culturales de la sociedad de la que emanan:

Las clasificaciones y los discursos sobre los animales que proponen las sociedades del pasado son siempre auténticos documentos históricos, con frecuencia de un gran interés, deben situarse en su contexto e interpretarse a la luz de los conocimientos de su tiempo, no a la luz de los conocimientos actuales... la historia natural es una forma particular de historia cultural (Pastoureau, 2008: 23-24).

Es este artículo recopilamos una serie de obras de arte, desde el medievo hasta nuestros días, en la cual los animales aparecen representados en el momento de orinar. ¿Cómo se ha representado el animal que orina en las distintas disciplinas artísticas? ¿Podemos encontrar en la Historia del Arte muchas imágenes de este género? ¿Son recurrentes? ¿Con qué finalidad se han utilizado? ¿Qué nos quieren decir?... El muestrario no es amplio, pero sí significativo desde el punto de vista iconográfico.

\section{Bestias salvajes y exóticas}

Los animales exóticos, originarios de países lejanos, durante mucho tiempo alimentaron la curiosidad de los artistas, ya que su presencia en Europa antes de comienzos del siglo XIX fue excepcional. Animales como rinocerontes, elefantes o leones estuvieron presentes en esculturas, artes suntuarias (tejidos, tapices, arquetas, etc.) y sobre todo en la pintura desde el medievo (códices miniados, bestiarios y marginalia en general). Si tenemos en cuenta que en los bestiarios, además de las especies reales descritas, apenas la mitad eran europeas, es decir conocidas para los hombres de aquella época, "esto puede explicar también la ingente cantidad de datos erróneos desde el punto de vista zoológico» que aportan estas compilaciones (Morales, 1996: 231). Además, muchos de ellos fueron copiados de grabados que circularon por toda Europa, sin que el artista jamás tuviera contacto con el natural (Mathis \& Sueur-Hermel, 2014: 19).

Un caso excepcional lo constituye la literatura de viajes, género cultivado desde la antigüedad, en el que las ilustraciones de animales realizadas in situ ofrecían a los lectores una ventana a mundos lejanos y exóticos.

\section{El camello}

En el amplio panorama de la literatura de viajes en la Europa del XVI destaca la aportación de André Thevet (15161590), un fraile franciscano, capellán de Catalina de Médicis y cartógrafo al servicio de cuatro reyes de Francia: Enrique II, Francisco I, Carlos IX y Enrique III, que en 1549 realizó un viaje a Oriente y que a su vuelta recogió todas sus impresiones y experiencias en un cuaderno de viajes publicado en 1554 con el título Cosmographie de Levant (Tous, 2015: 21). 


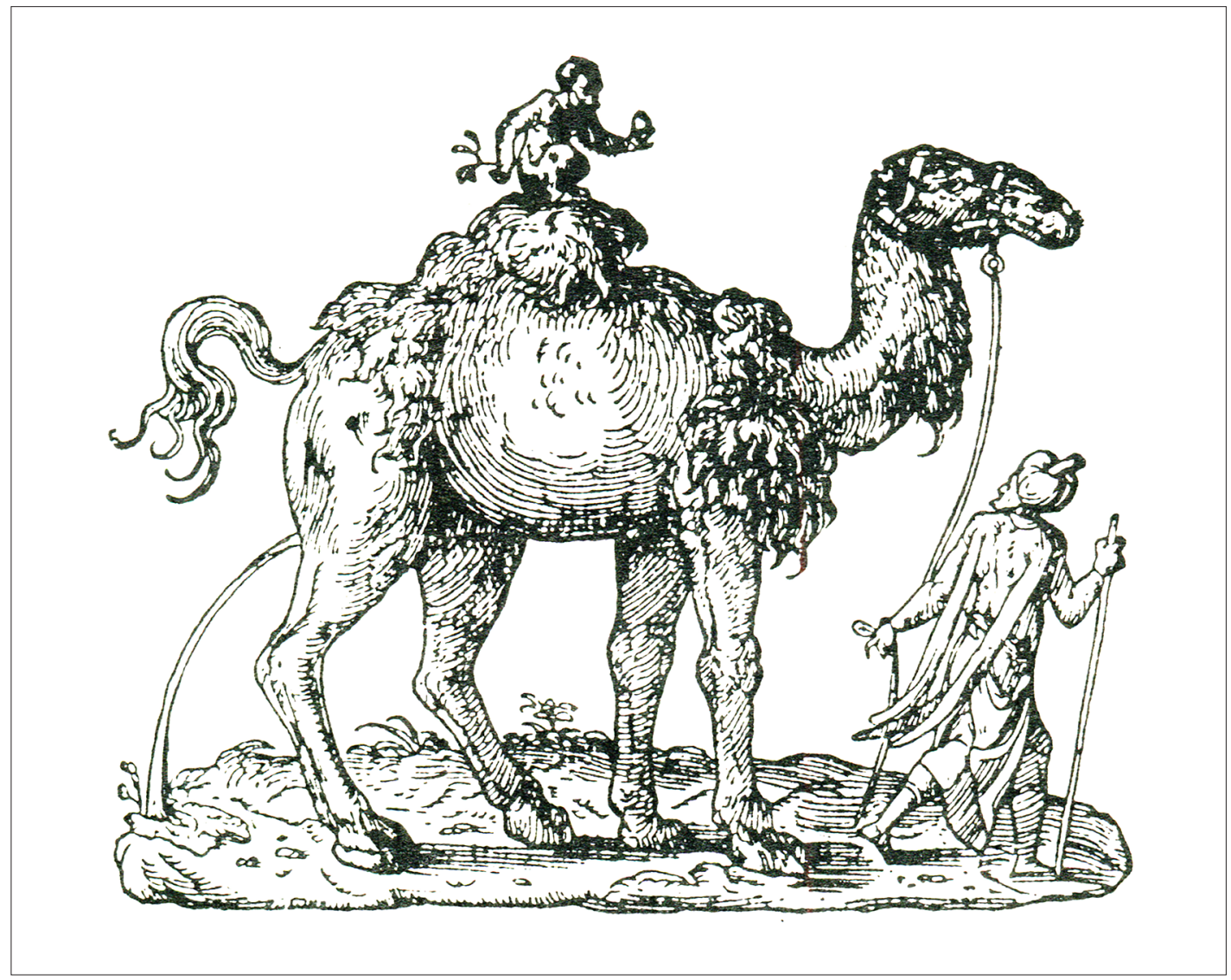

1. Camello. André Thevet d'Angoulême. Cosmographie de Levant, par F. André Thevet d'Angoulême. Revue et augmentée de plusieurs figures, Lyon, Jean Tournes et Guil.Gazeau, 1556, private collection, Aikaterini Laskaridis Foundation

En una de las xilografías que ilustran este libro de viajes aparece un camello orinando [1]. El camello (en realidad se trata de un dromedario ya que tiene una joroba) aparece portando un mono y guiado por un beduino. El animal, oriundo del norte de África y el Medio Oriente, aparece representado en el momento de orinar, al haberse detenido la marcha. El camello de Bactriana, o camello de doble giba, ya había sido descrito con exactitud por Aristóteles en su Historia animalium (Von Humboldt, 2011: 281), compendio de nueve libros escrito en el s. IV a. C., pero André Thevet añade un dato interesante para nuestro estudio al indicar que es el único mamífero que orina hacia atrás, a diferencia del resto, circunstancia perfectamente recogida en el grabado, y lo hace "de tal modo que el que estuviese detrás de ellos, si no se precaviese, se mojaría y contaminaría con su orina» (Leclerc, 1794: 64).
En el grabado del camello orinando de la Cosmographie de Levant aparece también representado un mono, animal que suele aportar una compleja simbología en los contextos icónicos en los que aparece.

\section{El mono}

El mono es uno de los animales más representados en los márgenes del arte medieval y en misericordias, ménsulas, arquivoltas y orlas sepulcrales, siendo su aparición en algunos casos tan numerosa que eclipsa a muchos otros del reino animal (Villaseñor, 2009: 106). En cuanto al término «simio", Villaseñor señala que es en el Physiologus en el que se explica que es denominado simia por su similitud con la razón humana (2009: 106). 


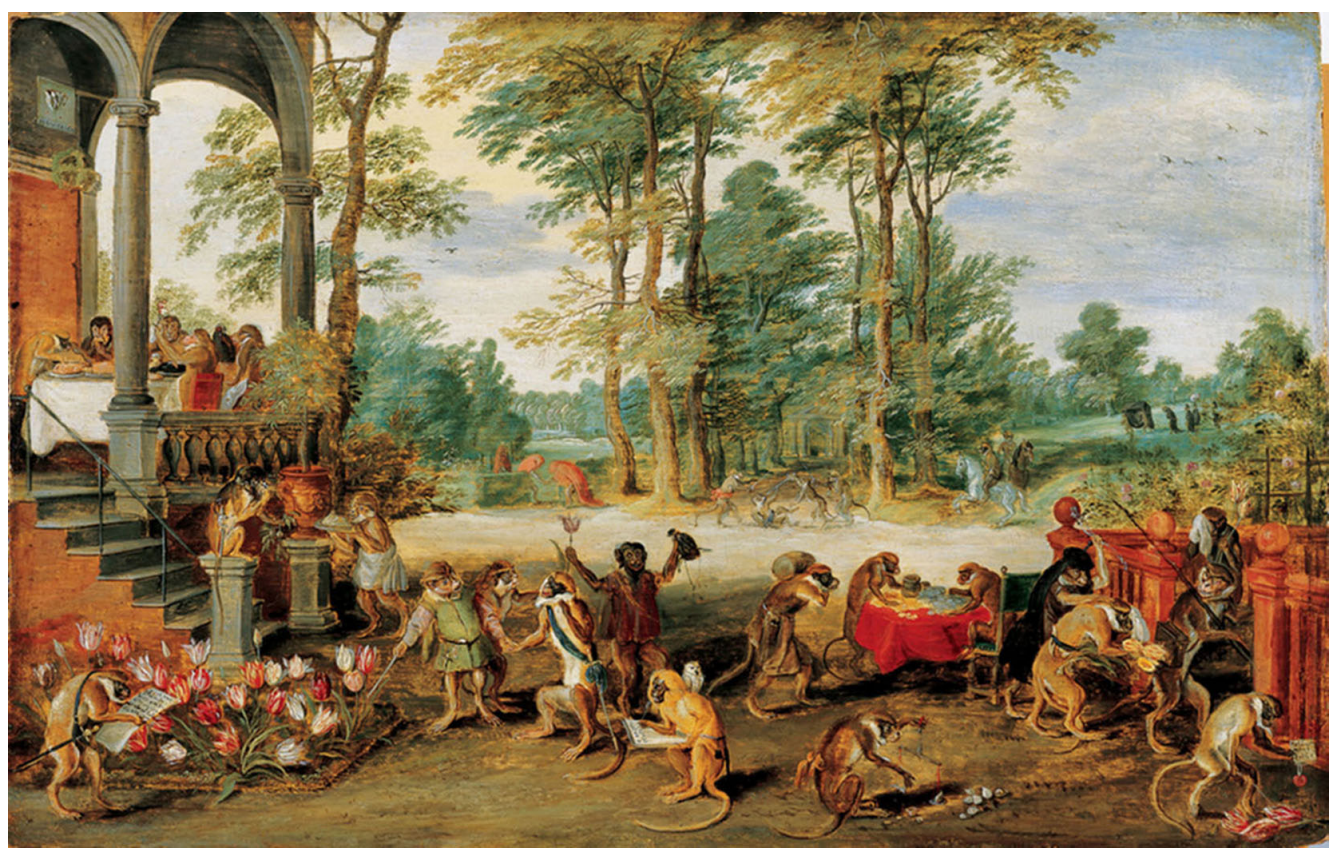

2. Alegoría de la Tulipomanía o Locura de los tulipanes, Jan Brueguel el Joven, ca. 1640, óleo sobre tabla, Frans Hals Museum, Haarlem (Países Bajos)

Esa similitud con el hombre ha sido ampliamente utilizada para personificar en el mono los vicios del género humano. Dos de sus significados más comunes son los de la lujuria y la avaricia: «Los simios pueden aparecer como emblemas de la usura o la lujuria, aunque también como símbolos de estatus social. Incluso cuando son representados con rasgos positivos, casi siempre hay un elemento de travesura o malicia en la imagen» (Walker, 2013: 63).

Estos significados simbólicos de la avaricia y la lujuria los encontramos presentes en dos conocidas obras flamencas: Las tentaciones de San Antonio de la estela de El Bosco (1450-1516) y la Alegoría de la Tulipomanía o Locura de los tulipanes de Jan Brueghel el Joven (1601-1678).

En un grabado anónimo de hacia 1522 de Las tentaciones de San Antonio, realizado a partir de una pintura de El Bosco, aparece la figura del mono en un comportamiento reprobable y obsceno, como es el de orinar sobre la imagen del santo que se encuentra recogido en penitencia. El mono, sentado sobre el techo del establo en el que se encuentra orando el santo en el desierto de la Tebaida (Egipto), descarga sobre él toda su inmundicia como signo de desprecio y de humillación. En este caso, además de hacer alusión a la luju- ria, personificada en el grabado por la dama con hennin que se acerca hacia el santo, el simio también representaría al diablo, culpable de todas las tentaciones que le atormentan:

\footnotetext{
Esta actitud cobró un giro mucho más negativo cuando el simio entró en el discurso de los escritores patrísticos. Conocedores del significado peyorativo de la palabra "simio", los autores cristianos la usaron para describir a todos los enemigos de Cristo, entre ellos los paganos, apóstatas, herejes e infieles. Sin embargo, la interpretación más perjudicial que pasó a la filosofía cristiana fue la que apareció en el Fisiólogo. Este texto afirma que el simio, junto con el asno salvaje, representa al diablo (Walker, 2013: 69).
}

La imagen del mono personificando la avaricia constituye la temática central de la Alegoría de la Tulipomanía o Locura de los tulipanes [2] de Jan Brueghel el Joven de hacia 1640. Esta singerie, «monería» u obra protagonizada por monos, tiene como principal valor iconográfico el antropomorfismo de los primates que aparecen representados parodiando las acciones humanas y personificando las consecuencias de la usura. 
El antropomorfismo animal es común en la representación de los monos por su cercanía física y comportamental con el hombre:

La ambigüedad existente entre la forma y el comportamiento de los simios respecto a los seres humanos hizo que estos fueran usados como espejo del comportamiento positivo y/o negativo de los hombres en representaciones tanto literarias como artísticas a lo largo de la historia (Walker, 2013: 63).

El mono personifica la imagen degradada del hombre y de sus errados comportamientos, aludiendo a los especuladores que desataron la crisis del tulipán en Holanda en febrero de 1637. Fue entonces cuando la especulación, en torno al comercio de los bulbos de esta flor, provocó el estallido de una burbuja financiera con la que muchos comerciantes se arruinaron. Brueghel representó este momento histórico de forma alegórica. En un palacete poblado de simios, vestidos conforme a los usos de los comerciantes adinerados holandeses, se celebra un copioso banquete de negocios, mientras los monos desempeñan tareas asociadas al mercadeo de esta flor: analizan atentamente las diversas especies de tulipanes, los cultivan, pesan los bulbos, cuentan el dinero, o emiten contratos de compraventa.

Conforme avanzamos en la lectura del cuadro, la situación va empeorando. Unos especuladores endeudados son detenidos y llevados ante un tribunal, otros lloran, y al fondo uno es enterrado víctima de la presión del momento. En el ángulo inferior derecho, un mono, mostrando un contrato devaluado en la mano, orina en señal de desprecio sobre las flores tiradas en el suelo que han perdido todo su valor en el mercado (Tongiorgi, 1995: 86).

\section{Animales domésticos}

Los animales domésticos han convivido con el hombre desde hace siglos y le han facilitado la vida y el trabajo. Precisamente por esa cercanía, suelen ser lo más representados en las artes. Entre los animales domésticos, los caballos y sobre todo los perros son los que han tenido un papel predominante que ha dado lugar a una florida literatura sobre la fidelidad canina, "considerándose este animal en el siglo XVIII como el más inteligente y la mejor compañía posible, lo que contrastaba con el status inferior asignado a los gatos, considerados demoníacos durante mucho tiempo» (Morgado y Rodríguez, 2011: 32-33).

\section{Perros}

Por su particular vinculación sentimental con el hombre, el perro ha tenido reservado un espacio de honor en la historia de la pintura:

Están en todas partes y a cualquier hora; dentro de las iglesias; en las plazas; en los palacios; en las chozas; con reyes y pordioseros. Ni siquiera faltan a la cita en instantes cumbres de la religión cristiana: Anunciación, Adoración de los Reyes, Sagrada Cena, Calvario... (Morales, 1992: 271).

Como adelanta Morales Padrón, incluso en las escenas cumbre de la religión los perros están presentes, y en casos excepcionales son representados orinando. En la Adoración de los Reyes Magos [3] de Tiziano (1490-1576) en el Museo del Prado, los reyes adoran al Niño siguiendo la iconografía tradicional, fijada desde la antigüedad. El Nacimiento se sitúa en el ángulo izquierdo. María tiene en su regazo a Jesús dispuesto para la adoración. Melchor se arrodilla para besarle el pie y Gaspar y Baltasar siguen aún montados en sus cabalgaduras.

A diferencia de otras muchas adoraciones en las que Jesús niño se representa totalmente desnudo porque «la exhibición del miembro sexual de Cristo sirve para certificar la humanación de Dios» (Steinberg, 1989: 26), en esta se muestra en forzado escorzo ocultando su humana condición.

Es Patricia Simons la que nos hace que reparemos en un detalle: Jesús está representado de lado, oculto su sexo a la vista del espectador e incluso a la vista de Gaspar que se afana en un giro de cabeza «mirando con insistencia para ver los genitales del recién nacido». La importancia otorgada a la representación de los genitales de Jesús niño a lo largo de la Historia del Arte ha sido constante para dejar clara su condición humana y sobre todo su género masculino. Pero lo curioso de esta Epifanía de Tiziano es que la ostentatio genitalium del Salvador vendría representada de forma vicaria mediante la presencia de un perro, en primer término, con la pata trasera levantada que orina, y que vendría intro- 


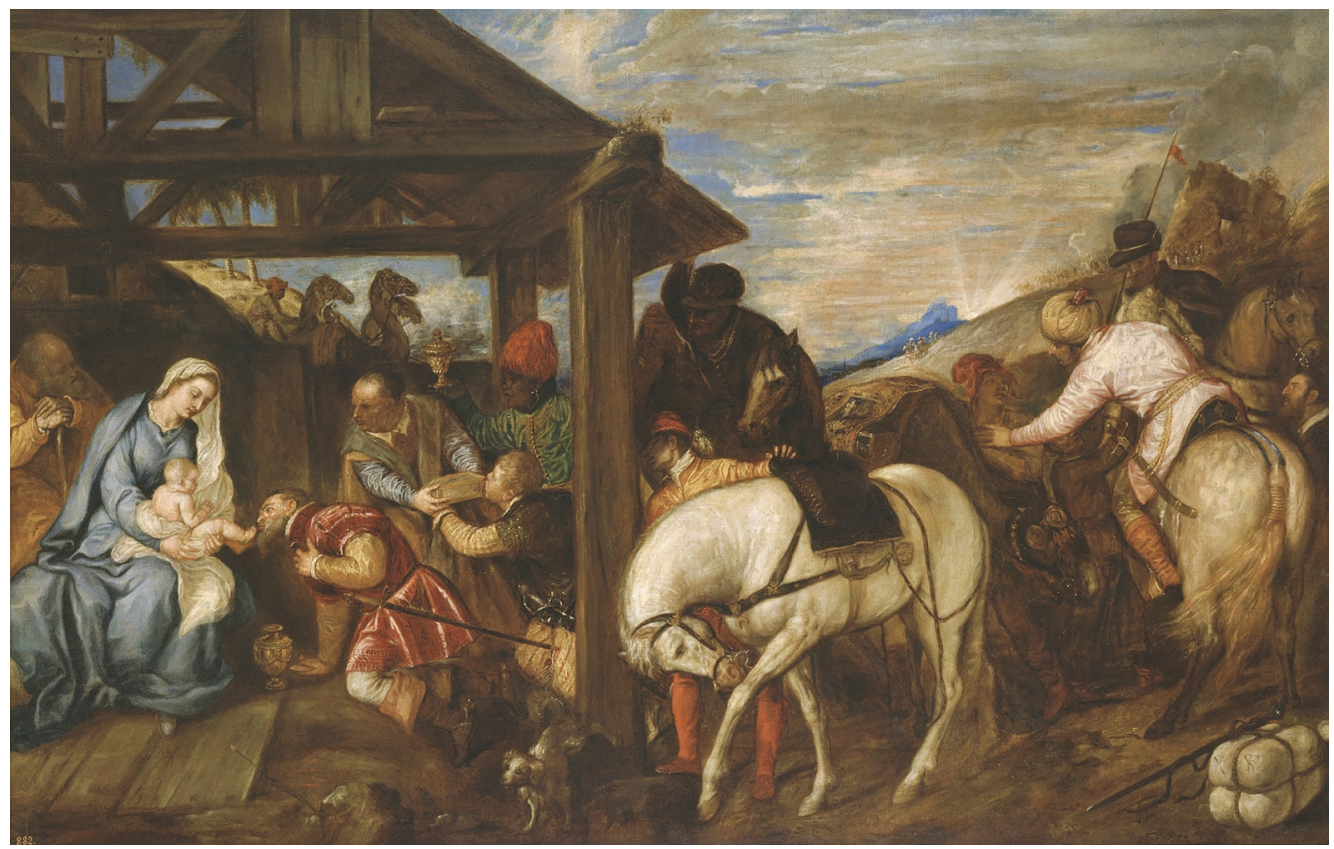

3. Adoración de los Reyes Magos, Tiziano, Vecellio di Gregorio, Siglo XVI, óleo sobre lienzo, 141 x 219 cm., Museo del Prado, Madrid (España)

ducida para informar a los espectadores que la encarnación verdaderamente terrenal del Hijo de Dios ha tomado forma de varón (2009: 335).

La orina poseería aquí el valor de reafirmar la verdad teológica de la escena representada1. El acto de orinar de forma libre y erguida, el perro no se agacha para hacerlo, tendría una connotación de masculinidad y virilidad otorgada tradicionalmente al hombre.

Los animales son los protagonistas indiscutibles de las fábulas, en las que se personalizan los vicios y virtudes de los hombres con una finalidad moralizante. En El perro y la picaza [4] de Paul de Vos (1596-1678) vemos a un perro de caza orinando como protagonista absoluto de la composición, ladrando a la picaza que vuela sobre él desafiándolo. La pintura se encuentra en el Museo del Prado y procede la Torre de la Parada, a las afueras de Madrid, en el Monte del Pardo, que tuvo una función primitiva como pabellón de caza real por lo que se explica la presencia de animales y escenas de caza en la decoración de sus paredes². La caza era una de las actividades preferidas por reyes, nobles y señores que gustaban de encargar obras de arte relacionadas con sus actividades cinegéticas en las cuales:
[...] los paisajes eran magníficamente pintados y su importancia era similar a la que el artista concedía al caballo, al perro y a la caza, en esos cuadros que querían ser, ante todo, expresión de la vida fastuosa de los gentilhombres. Estos exigían una pintura que representara los días durante los cuales habían practicado la montería, recordara las vicisitudes y los acontecimientos de sus correrías y evocara las proezas de sus caballos y perros (Skeaping, 1974: 204).

También aparece un perro orinando en Las Fábulas de Esopo con xilografías de Thomas Bewick (1753-1828), ornitólogo y grabador inglés, en concreto en la titulada La cerda y el lobo, de la edición de 1818 (Bewick: 134). Y del mismo Bewick encontramos representaciones de perros orinando en su libro Historia general de los cuadrúpedos (1792: 16 y 298). En estas xilografías, Bewick aprovechó su conocimiento de los hábitos de los animales obtenido durante sus constantes salidas al campo para representarlos de forma sintética pero magistral.

La visión de un perro orinando en la vía pública forma parte de nuestra vida cotidiana y así lo han entendido también los artistas contemporáneos que han elevado a la cate- 


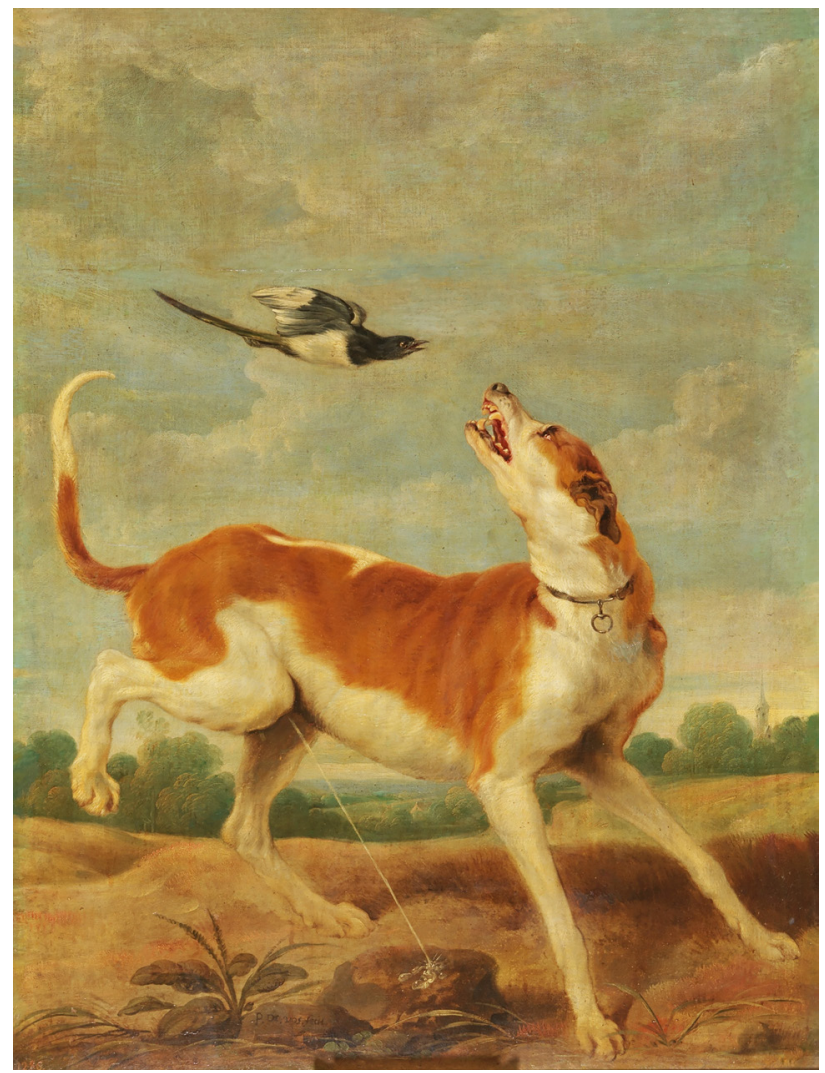

4. El perro y la picaza, Paul de Vos,1636-1638, óleo sobre lienzo, $115 \times 83 \mathrm{~cm}$, Museo del Prado, Madrid (España)

goría de arte esta simple circunstancia. Del ámbito del Street Art o arte urbano citamos un par de obras representativas de la presencia del perro callejero que orina. Het Zinneke, perro de orina, es una obra de Tom Frantzen (1954), correspondiente a la saga belga del Manneken Pis y de la Jeanneke Pis de Bruselas, completando así la «urotrilogía» urbana, histórica y turística de la ciudad. El artista local ha representado una escena callejera habitual, la del perro que levanta la pata trasera y orina en un póster del mobiliario urbano. En la web del propio artista se describe la obra como la representación de un chucho que representa el carácter multicultural de Bruselas. La estatua fue ordenada por el comité del distrito de Kartuizer para atraer turistas a la zona ${ }^{3}$.

En el ámbito de la arquitectura contemporánea llama poderosamente la atención la obra Bag Dog! (2013), del artista americano Richard Jackson [5], realizada en fibra de vidrio y materiales compuestos para The Orange Coun-

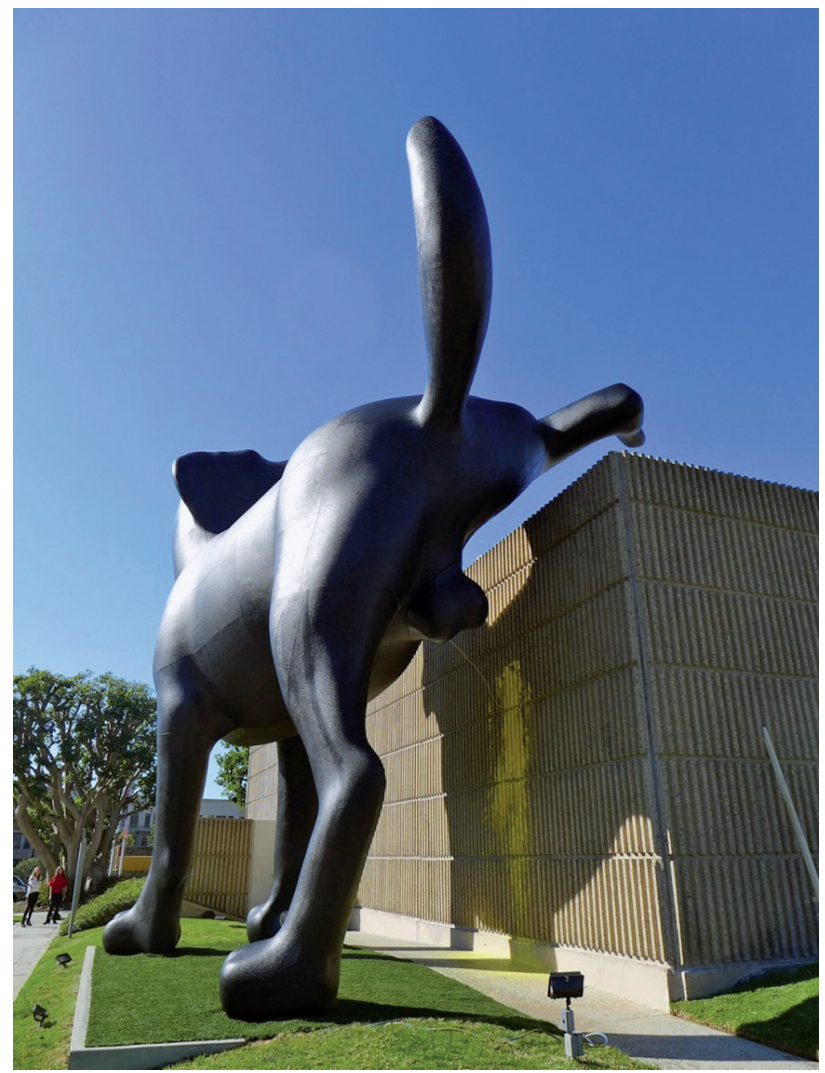

5. Bag Dog!, Richard Jackson, 2013, fibra de vidrio y materiales compuestos, The Orange County Museum of Art, Newport Beach, California (EE. UU.), Public Delibery

ty Museum of Art de Newport Beach, California. El artista escogió la figura de un labrador gigante de $8,5 \mathrm{~m}$ de alto para apoyarla sobre la fachada del museo durante su exposición «Ain' t Painting a Pain». El perro, que levanta una de las patas traseras para orinar, estaba dotado de un mecanismo que lo hacía expulsar pintura amarilla simulando la orina. La pieza pretendía ser un contrapunto simpático y a la vez descarado contra la corrección en los museos, el carácter aurático de los mismos y el elitismo en el mundo del arte.

Otros artistas como Banksy, que en febrero de 2011 pintó numerosos stencils en Los Ángeles, incluyendo entre ellos la temática del Perro orinando en un muro en Beverley Hills, Arthur Boris O'Klein (1893-1985), dibujante ruso de ascendencia francesa que desarrolló su actividad en París vendiendo caricaturas a los turistas sobre perros que orinan en posición erguida como los hombres -su serie más famosa es la titulada Perros sucios de París- o Manuel Iglesias, fo- 


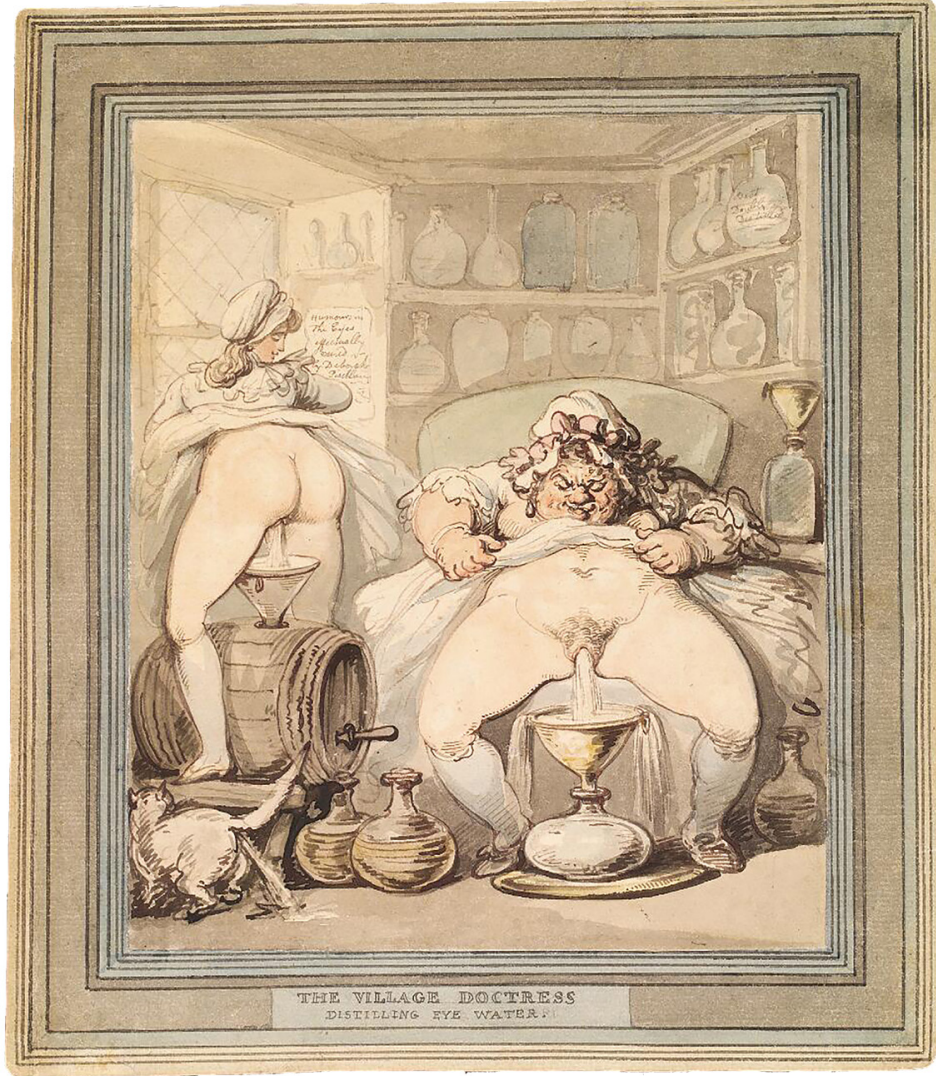

6. Una doctora de pueblo destilando un colirio, Thomas Rowlandson, ca. 1800, acuarela, Wellcome Library, n. ${ }^{\circ}$. 645283i tógrafo de EFE, que captó el momento preciso en el que un perro callejero mea a una monja, como un alegato antinacionalcatolicista, han utilizado este recurso icónico en sus producciones artísticas.

Gatos

Afirma Kenneth Clark que uno de los misterios que permanece inexplicable es la relativa escasez de gatos en el arte europeo (1977: 10). Esa escasez se acentúa si deseamos encontrarlos representados en el momento de la micción. Una excepción a esta regla se da en una acuarela satírica de Thomas Rowlandson (1756-1827) relacionada con las malas prácticas de curanderos y charlatanes.

La invasión de los charlatanes era tal en el siglo XVII que afirma Gambaccini que ningún periodo de la historia europea había conocido tal colmo de arrogancia y una invasión tan grande de vendedores de remedios, secretistas, alquimistas, aventureros y falsos profesionales que usaban el mercado de la medicina para su beneficio personal (2000: 229). Como suele ocurrir en estos casos, ignorancia y engaño solían ir de la mano, por lo cual el mundo rural era el espacio predilecto para sus actuaciones. Este tema no pasó por alto al ojo crítico de Rowlandson que satirizó la labor de los charlatanes en una soez acuarela titulada Una doctora de pueblo destilando un colirio [6] de hacia 1800 en la que la supuesta doctora, representada sin ningún tipo de escrúpulo, ni corporal, ni moral, recoge con un embudo el caudal de su abundante orina, así como la de su joven manceba y hasta la del gato, para destilar un remedio que venderá para las dolencias oculares, posiblemente cataratas. La presencia del gato, asociada a valores cambiantes a lo largo de la historia, ha fluctuado «desde la época clásica hasta la renacentista, pasando por un patrón demonológico iniciado en los siglos medievales, así como su integración como animal de compañía a finales del siglo XVIII» (Agudo, 2011: 131), aunque su presencia suele connotar negatividad como afirma Morales Muñiz, asociándolo a la traición (1996: 244) o, según Agudo Rey, por influencia de la Iglesia asociándolo al 
demonio, la muerte, la herejía, la brujería, y consideraciones negativas de carácter sexual (2011: 133).

\section{Caballos}

Los caballos fueron el principal motivo animal en dibujos y grabados entre los siglos XVII al XIX, y dentro de ellos, su representación orinando fue especialmente querida por la escuela flamenca de los siglos XVII y XVIII, cuyos grabadores representaron con insistencia al animal de esta guisa:

Pieter van Laer (1599-1642) realizó una serie de seis grabados bajo el título Conjunto de caballos, en la cual describe un sombrío lote de animales pertenecientes a pobres campesinos. El grabado número 3 de la serie representa a un caballo, llevado por su dueño a pie, que detiene la marcha para orinar. El grabado muestra al caballo en una condición física razonablemente buena pero la última impresión de la serie presenta dos caballos muertos (Brinkmann, 1993: 132).

Jan van Aken (1624-1700) realizó una serie denominada Paisaje con caballos, en la que uno de ellos, Caballo orinando, presenta al animal de esta forma en primer plano. Entre las patas se puede ver a un campesino sentado de espaldas y a la derecha aparece un segundo caballo también de espaldas al espectador ${ }^{4}$.

A Jan Peeter Verdussen (1700-1763) pertenece el grabado Carro con caballo enojado en un paisaje, de la serie Paisajes y caballos, descrita en la ficha catalográfica del Rijksmuseum como grabado que representa un amplio paisaje en que se ve en primer plano un carruaje tirado por tres caballos, un cochero, y a la derecha un perro ${ }^{5}$. El título del grabado hace alusión al empecinamiento del animal en parar la marcha del carro para orinar.

Todos estos pintores y grabadores de paisajes y de escenas de género coinciden a la hora de representar a los caballos en paisajes abiertos, como elemento principal de la composición o en compañía de sus dueños, generalmente campesinos o cocheros de condición humilde.

Mención aparte merecen un par de obras en las que el acto de orinar de los caballos aparece sincronizado con el de sus jinetes. En un dibujo de Horace Vernet (1789-1983), firmado y fechado en 1820, un Lancero rojo a caballo de la guardia imperial francesa, visto de espaldas, orina, al mismo tiempo que lo hace el caballo sobre el que va montado. Vernet fue pintor especializado en batallas, en las que representó al ejército francés con un chovinismo exacerbado en sus principales campañas militares, por lo que llama la atención esta forma tan banal y antiheroica de representar al soldado.

Cerramos el capítulo de los caballos con otro grabado satírico de Thomas Rowlandson perteneciente a la colección de estampas del British Museum titulado Sympathy, or a family on a journey laying the dust o Simpatía, o una familia de viaje asentando el polvo [7]. Efectivamente, la imagen muestra con sátira a una familia formada por un padre, madre, hija y perro, que, junto con el cochero y los dos caballos, orinan todos en una parada durante su viaje a «Broadwater», nombre que aparece escrito en una señalización del camino. Evidentemente la sátira se encuentra presente tanto en el nombre de la ciudad a la que se dirigen "Broadwater», «Agua ancha» o «Agua amplia», haciendo alusión a la escena en la que todos están representados «haciendo aguas», como en el título del grabado que hace alusión a la finalidad que consiguen con la escena de orina colectiva: asentar el polvo que el coche de caballos ha levantado durante su marcha y que aparece representado como una densa nube en segundo plano.

\section{Ganado}

En las representaciones de animales domésticos el ganado también ocupa un lugar destacado y, dentro del ganado, los bovinos y los ovinos son los predilectos por los pintores y grabadores holandeses del siglo XVII para mostrarlos en el momento de orinar, vista esta habitual en el mundo ganadero.

Paulus Potter (1625-1654) fue uno de los más célebres pintores animalistas de su época (Mezzalira, 2013: 188). Potter fue un pintor muy prolífico que otorgó a los animales una posición de suma importancia en sus composiciones y fue uno de los primeros artistas en representarlos como sujetos por derecho propio, cuidando los detalles y el realismo en la representación (Wheelock Jr., 2014). Cabras, ovejas, cerdos, y principalmente vacas son los motivos centrales de sus cuadros y grabados en los que no es difícil encontrarlos orinando, como ocurre en el dibujo titulado Cerdos y Paisaje del Museo Condé (Chantilly) en el que una manada de 


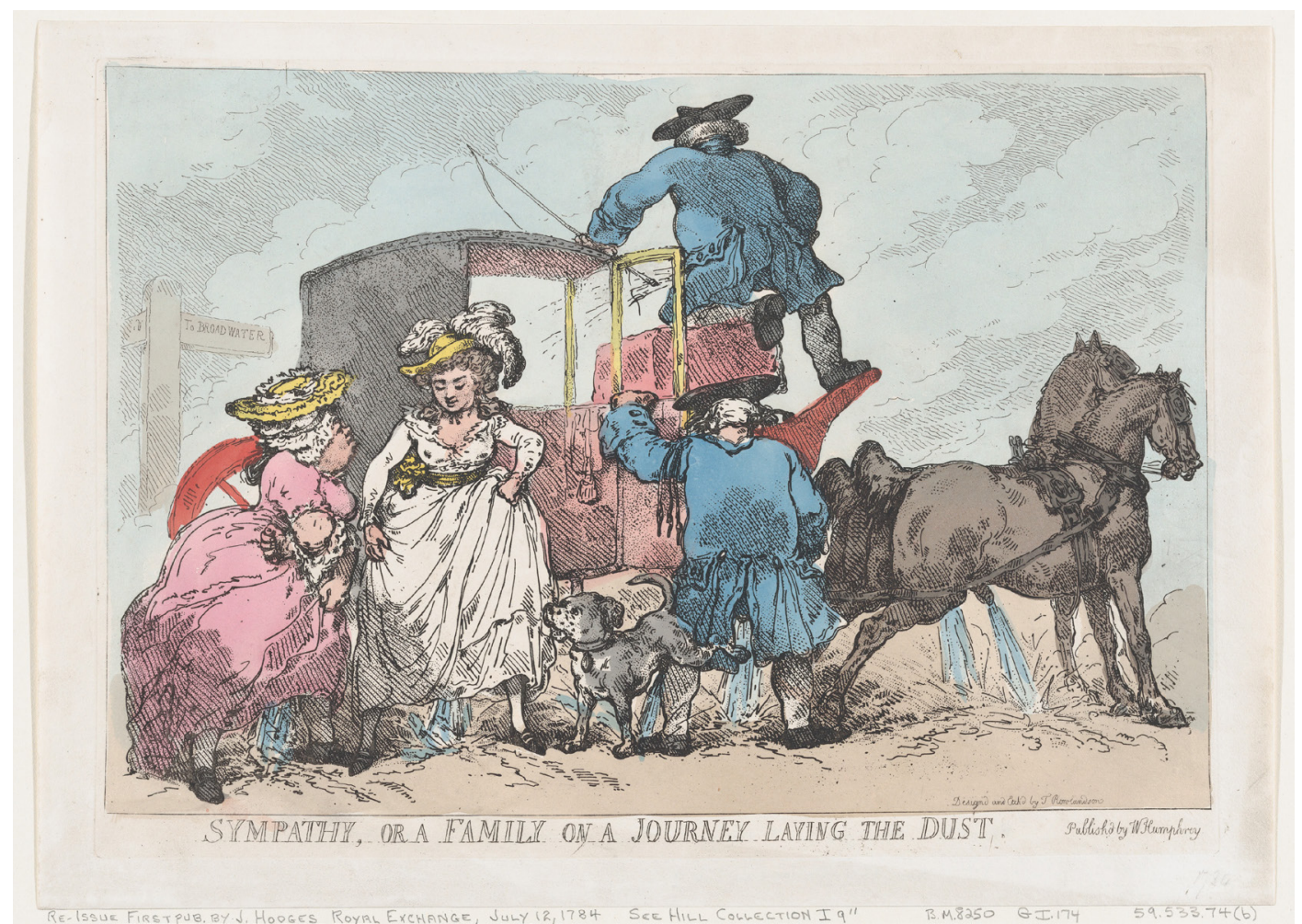

7. Sympathy, or a family on a journey laying the dust, Sympathy, Thomas Rowlandson, William Humphrey (editor), publicado en Londres en 1784, grabado iluminado, $27.6 \times 38.4$ cm., impresión: $24.8 \times 34.9$ cm., The Elisha Whittelsey Collection, The Elisha Whittelsey Fund, 1959, The Metropolitan Museum of Art New York (EE.UU), n. ${ }^{0}$ 59.533.74(b)

cerdos sestea, mientras uno de ellos orina (Skeaping, 1974: 196), o en su popular Vaca orinando que ha sido copiada en numerosas ocasiones por pintores y grabadores.

Contemporáneo de Paulus Potter fue, el también holandés, Nicolaes Pietersz Berchem (1620-1683), pintor y grabador de paisajes y escenas pastorales, que alcanzó gran popularidad en su tiempo, y en cuya obra gráfica encontramos varios ejemplos de cabras y vacas orinando: Cabra orinando / y Cabra orinando // de entre 1648-1650 en el Musée des Beaux-Art d'Orléans de Lyon; y la Familia de pastores durmiendo (La vaca orinando) [8] de entre 16501652, grabado que se encuentra en la colección de estampas de la National Gallery of Art de Washington, en el que la vaca orinando de Paulus Potter parece que fue una importante fuente de inspiración aunque el estilo de Berchem en más fresco y flexible gracias a un sombreado menos intenso (Wuestman, 2006: 124). Wuestman nos dice que la vaca está «pontificalmente colocada» en medio de una escena pastoril en la que no falta el gallo, posado sobre la puerta de la cabaña, el asno, las cabras y una familia, padre, madre e hija, que sestean.

A menudo, estas estampas mostraban la vida pastoril apacible y tranquila con una fuerte carga bucólica que se ofrecía como contrapunto a la vida de las grandes ciudades, como ocurre en La vaca curiosa, obra de Jan Siberechts (1627-1703), también pintor paisajista y animalista flamenco, en la que la escena costumbrista y bucólica del carro vadeando el río se ve interrumpida de pronto porque una vaca se ha detenido a orinar en medio de la corriente fluvial, mirando directamente al espectador y haciéndole partícipe de una escena de la que Skeaping dice que es «iRealismo a todo precio! Pero la anécdota no deja de ser viva y sabrosa» (1974: 198).

En el ámbito de la pintura española del Siglo de Oro, y dentro del repertorio de obras atribuidas a Pedro Núñez de Villavicencio (1644-1695), pintor sevillano que cultivó la pin- 
8. Vaca orinando, Nicolaes Pietersz Berchem, siglo XVII, grabado, Hollstein, no. 2, State ii/v. Ailsa Mellon Bruce Fund., n. ${ }^{\circ}$ 1972.28.3, National Gallery of Art, Washington (EE.UU.)

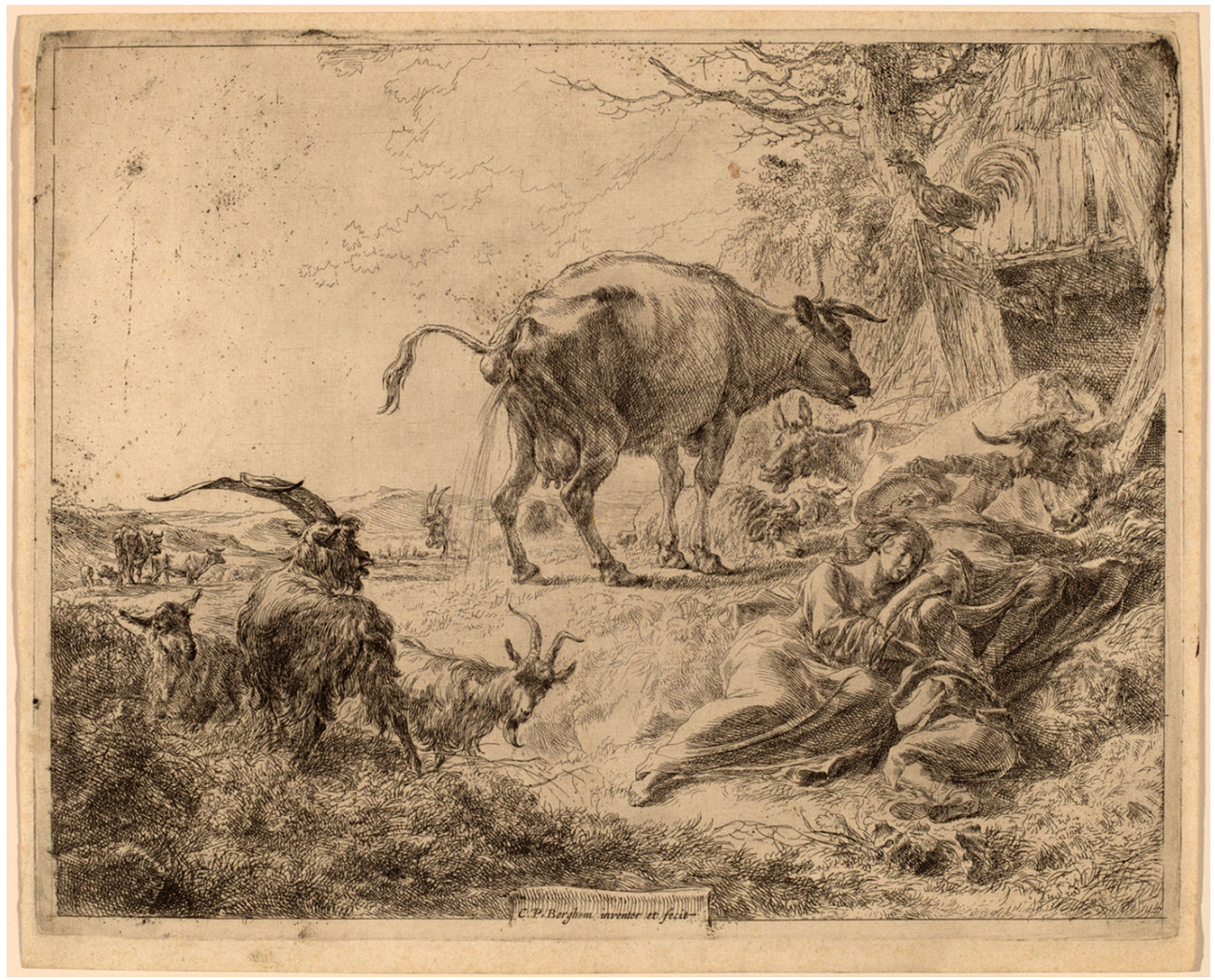

tura de género popular, encontramos una escena en la que un chiquillo guarda el ganado y señala, con cara de pícaro, el chorro de orina de la vaca que está junto a él. Aunque la autoría de esta obra es atribución, si nos guiamos por la cronología de Martínez Ripoll, habría que datarla en la década de 1680:

Aunque no puede descartarse que sus cuadros de género los pintara ya con anterioridad -lo que es muy posible-, debió ser a lo largo de la década de los ochenta cuando más se dedicaría a pintar esos «muchos cuadros de su invención, siguiendo el estilo de Murillo en algunos juguetes de chulillos desarrapados hechos por el natural» $\mathrm{y}$ «ejecutado[s] con extrema gracia y propiedad» (Palomino) (Martínez, 1982: 109).

\section{Monstruos}

La figura del monstruo toma todo su significado por oposición con lo ordinario. Kappler afirma que en el imaginario medieval "el monstruo es una "anomalía normal", un avatar necesario, inevitable, misterioso pero no dramático de la imaginación y de la creación divina» y que para el hombre normal los monstruos son «formas diferentes de él mismo. Esas formas son el resultado de una organización no habitual de los elementos ordinarios de composición, de un amasijo diferente de la materia inicial» (1986: 132).

Entre los mecanismos de creación e invención de monstruos, uno de los más habituales fue el de la «hibridación» o «mezcla de elementos anatómicos dispares que alteran el aspecto físico normal», siendo la hibridación monstruosa más frecuente la que mezcla elementos humanos y animales (1986: 167), como es el caso del Demonio, Lucifer o Satanás. En el Renacimiento, el monstruo era la imagen de la degradación del mundo, supuesto signo de la ira de Dios (Mathis \& Sueur-Hermel, 2014: 22) y en el epicentro de lo monstruoso se encontraba el demonio, descrito o representado en numerosas ocasiones bajo la forma de animales en «la literatura patrística, y medieval, especialmente la de carácter devocional» (Eco, 2007: 92). 


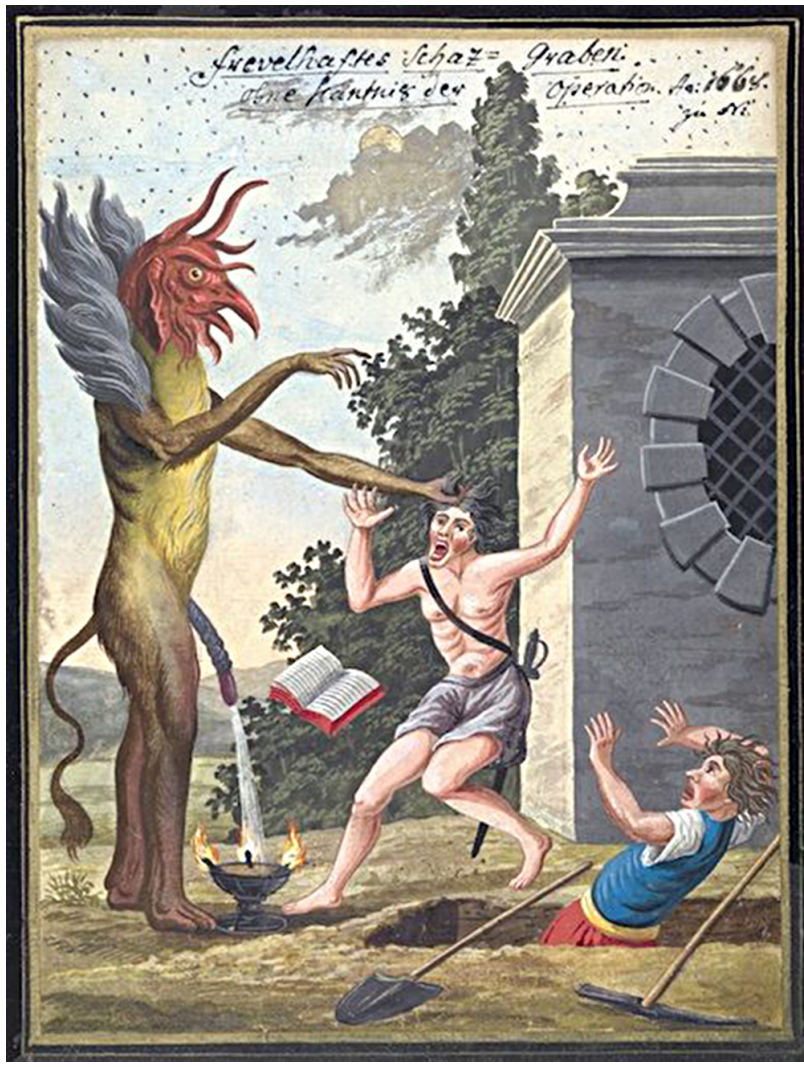

9. Demonio, en Compendium rarissimum totius Artis Magicae sistematisatae per celeberrimos Artis hujus Magistros. Anno 1057. Noli me tangere, ca. 1775, Wellcome Library, Ref. MS1766.

\section{Demonio}

El demonio es la representación del mal por antonomasia en la cultura cristiana occidental, la figura antagonista de Cristo, y su existencia se justifica porque el mal es un componente de la dinámica de la vida, bien y mal existen y conviven sobre la faz de la tierra (Paparoni, 2017: 36).

Vamos a analizar dos tipos de imágenes en las que aparece el demonio, unas procedentes del ámbito de la brujería, en un tiempo en el que la práctica de estos ritos estaba aún penado con la muerte y el demonio era temido y otras en las que la imagen del maligno se muestra completamente desacralizada y vacía de cualquier significado religioso, mostrándose incluso caricaturizada. Ambas, en cambio, tienen el denominador común de mostrarnos al demonio orinando.

En torno al año 1775, aparece el libro Compendium rarissimum totius Artis Magicae sistematisatae per celeberri- mos Artis hujus Magistros. Anno 1057. Noli me tangere que se traducir como «Un raro resumen de todo el Arte Mágico de los Maestros más famosos de este Arte. Año 1057. No me toques», un tardío libro de magia y rituales de ocultismo en el que comparece una serie de criaturas fabulosas. Decimos que su publicación fue tardía porque «la última ejecución por brujería en Inglaterra tuvo lugar en 1716 (1727 en Escocia, 1750 en Austria, 1782 en Suiza), mientras que la práctica de la brujería dejó de ser un delito penal en toda Europa durante el siglo (Inglaterra 1735)»6.

El volumen está escrito en una mezcla de alemán y latín y contiene 31 acuarelas del diablo y de seres demoníacos junto con tres páginas de magia y símbolos rituales ocultos. En una de estas acuarelas aparece la figura del demonio orinando sobre una lámpara de aceite [9] .

En un camposanto dos hombres cavan una tumba, en lo que pudiera ser un acto de profanación. Sabemos que la escena se desarrolla de noche porque aparece iluminada por una lámpara de aceite y en alto se puede ver la luna, semioculta por unas nubes, y las estrellas. El demonio aparece en escena ante la cara de horror de los presentes, agarrando a uno de ellos de forma violenta por el pelo y apagando con su orina la lámpara. La llama que se apaga es símbolo inequívoco de muerte. El diablo aparece representado de forma antropomorfa, con partes del cuerpo pertenecientes a distintos animales como el rabo y las garras, la abundante pilosidad, la cabeza mitad dragón, mitad pájaro, y un pene propio de una bestia, asno o caballo, del que fluye la orina.

El diablo ocupa todavía hoy un lugar destacado en el imaginario colectivo de nuestra sociedad, si bien es cierto que ha perdido el carácter sacro, divino o religioso que tuvo en el pasado. Sigue manteniendo la misma iconografía, fijada en el medievo y en el Renacimiento, pero ahora comparece, más que con un carácter divino, como un encantador malvado o como un genio maligno, propio de cuentos y fábulas (Paparoni, 2017: 33). Así lo vemos en la publicidad, en el cine, en el comic, videojuegos y tatuajes. Muchos artistas en las últimas décadas han tratado el tema como Keith Haring, Robert Mapplethorpe, Andrés Serrano, Tony Oursler, Richard Phillips, Ronald Ventura y Manuel Ocampo, entre otros.

Evidentemente no todos han representado al demonio en el acto de orinar, ni siquiera una minoría lo ha hecho, pero en la obra de Manuel Ocampo (1965), pintor filipino contem- 
poráneo, sí encontramos una representación interesante, vinculada también al ámbito de la brujería. En su obra Lysol, panel central del tríptico titulado Hoover, Lysol, Zonrox de la serie Demons Dance Alone, el demonio aparece agachado, apoyado en el suelo con su mano izquierda mientras que con la otra se separa las nalgas para mostrarle al espectador la abertura del ano. El acto es una invitación al espectador a besarle el culo, al Osculum infame, como alusión al gesto reverencial que hacían las brujas de besar la otra «boca» del diablo durante las ceremonias del aquelarre o Sabbat (Paparoni, 2017: 298). Al tiempo que mira al espectador en su particular invitación, babea y se orina.

\section{Gárgolas}

Parecería lógico que entre las gárgolas, cuya función principal es la de expulsar agua y que lo hacen habitualmente por los distintos orificios corporales, se encontrasen representaciones de animales y seres fantásticos orinando, en definitiva, parecería una función natural para ellas. En cambio, no es así. Sí aparecen vertiendo agua por la boca, lo más común, e incluso por el ano, pero no por el pene.

Esta ausencia, sobre la que se detiene Janetta Rebold Benton en su monografía sobre las gárgolas en los edificios medievales, le hace llegar a la conclusión de que existir tuvieron que existir, pero no han llegado hasta nuestros días (1997: 65). Una excepción la encontramos en Lonja de la Seda o Lonja de los Mercaderes de Valencia, "considerado como el más emblemático de los edificios del gótico civil valenciano, comenzó a construirse en 1483 por Pere Compte y Joan Ibarra, a iniciativa del municipio» (La Lonja) en la que una de las 28 gárgolas monstruosas que adornan las cornisas exteriores del edificio es una Gárgola que orina y representa una hibridación antropo-zoomórfica de hombre-animal alado que se sujeta el pene para orinar dentro de una jarra. En las gárgolas hay una gran cantidad de figuras híbridas de apariencia antropomorfa (Herrero, 2016: 77), aunque su aparición en este edificio tiene un significado incierto:
Nadie sabe a ciencia cierta qué significan estas figuras. Una de las tesis más aceptadas es que tenían un objetivo moralizante, explicar a los que las vieran cuáles son los pecados más indignos o incluso como admonición contra ellos. Otros apuestan por el carácter satírico y de denuncia contra las prácticas de la época. Y hay quien asegura que con ellas lo que se pretendía es espantar a los demonios y los vicios, que quedaran fuera del edificio ${ }^{8}$.

\section{Conclusión}

En este recorrido temático por la representación del animal que orina, nos hemos aproximado a un microuniverso representacional, residual dentro del arte. Al igual que los animales han sido representados corriendo, pariendo, huyendo, cazando y siendo cazados, devorando y siendo devorados, jugando, o simplemente muertos y cocinados, también se les ha representado orinando, como hecho anecdótico y trivial la mayoría de las veces. En las escenas de género, muy del gusto de los pintores flamencos tan amantes de la naturaleza y de la representación minuciosa de los seres que la habitan, el animal que orina aparece como escena habitual de la vida rural, sin pretextos, ni contextos religiosos sino simplemente por el placer de observarlos y con un amor que no ha sido superado en la historia de la representación animal (Clark, 1977: 77). A veces, el acto de la orina viene acompañado de risa por parte del espectador que encuentra el hecho simpático, por la fuerza o el caudal del chorro de orina animal, o incluso grotesco ya que desde la Edad Media la gente ha tenido la tendencia de considerar como grotescas las imágenes que enfatizan las relaciones entre el cuerpo y sus funciones físicas (comer, orinar, defecar, etc.). En otros casos, la representación del animal orinando tiene una función de humillación o desprecio hacia el sujeto/objeto sobre el que proyecta su orina, vinculada a supuestos sociales, políticos, religiosos o morales, y en otras, alude a significados más complejos relacionados con la sexualidad, la masculinidad y la fertilidad. 


\section{Notas}

1 «Perchè Tiziano dipinse un cagnolino che faceva pipì nella capanna e perchè fu cancellato». En: <https://www.stilearte.it/perche-tiziano-dipinse-un-cagnolino-che-faceva-pipi-nella-capanna-e-perche-fu-cancellato/> (fecha de consulta: 25-02-19).

2 «El perro y la picaza». En: <https://www.museodelprado.es/coleccion/obra-de-arte/el-perro-y-la-picaza/fd3bb886-256a-49d9-ac51-c12177707898?searchMeta=picaza> (fecha de consulta: 25-02-19).

3 «Straatsculpturen». En: <http://www.tomfrantzen.be/nl/artr.htm> (fecha de consulta: 25-02-19).

4 «Pissend paard, Jan van Aken, 1624-1700». En: <http://hdl.handle.net/10934/RM0001.collect.71294> (fecha de consulta: 25-02-19).

5 «Rijtuig met pissend paard in een landschap, Jan Peeter Verdussen, 1710-1763». En: <https://www.rijksmuseum.nl/en/collection/RP-P-2005-279> (fecha de consulta: 25-02-19).

6 «llustraciones demoniacas de un libro de ocultismo del siglo XVIIl». En: <http://imagomagazine.net/ilustraciones-demoniacas-de-un-libro-ocultismo-del-siglo-xviii/> (fecha de consulta: 25-02-19).

7 "Compendium rarissimum totius Artis Magicae sistematisatae per celeberrimos Artis hujus Magistros. Anno 1057. Noli me tangere». En: <https://wellcomelibrary.org/item/b1968583x\#?m=0\&cv=34\&z=-0.1806\%2C-0.1796\%2C1.3984\%2C0.8784\&c=0\&s=0> (fecha de consulta: 25-02-19).

8 A., C. «Porno 'a la piedra': el enigma de las gárgolas obscenas de la Lonja». En: <http://epoca1.valenciaplaza.com/ver/118795/porno-a-la-piedra-el-enigma-de-las-gargolas-obscenas-de-la-lonja.html> (fecha de consulta: 25-02-19).

\section{Bibliografía}

A. C. «Porno "a la piedra": el enigma de las gárgolas obscenas de la Lonja». En: <http://epoca1.valenciaplaza.com/ver/118795/porno-a-lapiedra-el-enigma-de-las-gargolas-obscenas-de-la-lonja.html> (fecha de consulta: 25-02-19).

AGUDO REY, Cristina (2011), «El gato en History of foure-footed beasts de Edward Topsell», en MORGADO GARCÍA, Arturo y RODRÍGUEZ MORENO, José Joaquín, Los animales en la historia y en la cultura, Servicio de Publicaciones de la Universidad de Cádiz, Cádiz, pp. $131-141$.

BEWICK, Thomas (1792), A General History of Quadrupeds, Newcastle upon Tyne, Printed by and for S. Hodgson, R. Beillby, \& T. Bewick, Newcastle.

- (1818), The fables of Aesop, and others, E. Walker for T. Bewick and son. Sold by them, Longman and Co. London, and all booksellers, Newcastle.

BRINKMANN PIMENTEL, Ursula M. (1993), Dutch and Flemish Art at The Utah Museum of Fine Arts. A Guide to The Collection, The Utah Museum of Fine Arts, University of Utah, Salt Lake City.

CLARK, Kenneth (1977), Animals and Men, Thames and Hudson, London.

«Compendium rarissimum totius Artis Magicae sistematisatae per celeberrimos Artis hujus Magistros. Anno 1057. Noli me tangere». En: <https://wellcomelibrary.org/item/b1968583x\#?m=0\&cv=34\&z=-0.1806\%2C-0.1796\%2C1.3984\%2C0.8784\&c=0\&s=0> (fecha de consulta: 25-02-19).

ECO, Umberto (2007), Historia de la fealdad, Lumen, Barcelona.

«El perro y la picaza». En: <https://www.museodelprado.es/coleccion/obra-de-arte/el-perro-y-la-picaza/fd3bb886-256a-49d9-ac51 -c12177707898?searchMeta=picaza> (fecha de consulta: 25-02-19).

GAMBACCINI, Piero (2000), I mercanti della salute. Le segrete virtú dellímbroglio in medicina, Casa Editrice Le Lettere, Firenze.

HERRERO FERRIO, Dolores (2016), «La gárgola en el mundo hispano bajomedieval», Revista Digital de Iconografía Medieval, vol. VIII, n. ${ }^{\circ}$ 16, pp. 67-99.

«llustraciones demoniacas de un libro de ocultismo del siglo XVIIl». En: <http://imagomagazine.net/ilustraciones-demoniacas-de-un-libro-ocultismo-del-siglo-xviii/> (fecha de consulta: 25-02-19).

KAPPLER, Claude (1986), Monstruos, demonios y maravillas a fines de la edad media, Akal Universitaria, Móstoles. «La Lonja». En: <http://www.museosymonumentosvalencia.com/monumentos/la-lonja/> (fecha de consulta: 25-02-19). LECLERC, Georges-Louis (1794), Historia natural, general y particular. Volumen XIII, Imprenta de la Viuda de Ibarra, Madrid.

MARTínEZ RIPOLL, Antonio (1982), «Para una cronología de Pedro Núñez de Villavicencio», Goya, Revista de Arte, n. 169-171, pp. 105-112. 
MATHIS, Rémi \& SUEUR-HERMEL, Valérie (2014), «Une estampe, des estampes», en MATHIS, Rémi \& SUEUR-HERMEL, Valérie (coords.), Animal, Bibliothèque Nationale de France, París, pp. 19-22.

MEZZALIRA, Francesco (2013), Le immagini degli animali tra scienza, arte e simbolismo, Angelo Colla Editore, Costabissara (Vicenza).

MORALES MUÑIZ, M. ${ }^{a}$ Dolores-Carmen (1996), «El simbolismo animal en la cultura medieval», Espacio, Tiempo y Forma, Serie III, Ha Medieval, t. 9, pp. 229-255.

MORALES PADRÓN, Francisco (1992), "Los perros en la pintura», Laboratorio de Arte, n. 5, pp. 265-274.

MORGADO GARCÍA, Arturo y RODRíGUEZ MORENO, José Joaquín (2011), Los animales en la historia y en la cultura, Servicio de Publicaciones de la Universidad de Cádiz, Cádiz.

MUÑOZ, Juan (1984), La imagen del animal. Arte Prehistórico. Arte Contemporáneo, Caja de Ahorros y Monte de Piedad de Madrid, Madrid. PAPARONI, Demetrio (2017), The Devil. Attlante illustrato del lato oscuro, 24 Ore Cultura, Milano. «Pissend paard, Jan van Aken, 16241700». En: <http://hdl.handle.net/10934/RM0001.collect.71294> (fecha de consulta: 25-02-19).

PASTOUREAU, Michel (2008), El oso. Historia de un rey destronado, Paidós, Barcelona.

REBOLD BENTON, Janetta (1997), Holy Terrors. Gargoyles on Medieval Buildings, Abbeville Press, London.

«Perchè Tiziano dipinse un cagnolino che faceva pip̀̀ nella capanna e perchè fu cancellato». En: <https://www.stilearte.it/perche-tiziano-dipinse-un-cagnolino-che-faceva-pipi-nella-capanna-e-perche-fu-cancellato/> (fecha de consulta: 25-02-19).

«Rijtuig met pissend paard in een landschap, Jan Peeter Verdussen, 1710 - 1763». En: <https://www.rijksmuseum.nl/en/collection/RP-P2005-279> (fecha de consulta: 25-02-19).

SIMONS, Patricia (2009), "Manliness and the Visual Semiotics of Bodily Fluids in Early Modern Culture», Journal of Medieval and Early Modern Studies, 39:2, pp. 331-373.

SKEAPING, John (1974), Las fuentes del arte. Los animales en el arte. De la prehistoria a nuestros días, Librería Editorial Argos, Barcelona. STEINBERG, Leo (1989), La sexualidad de Cristo en el arte del Renacimiento y en el olvido moderno, Hernan Blume, Madrid.

«Straatsculpturen». En: <http://www.tomfrantzen.be/nl/artr.htm> (fecha de consulta: 25-02-19).

«Sympathy, or a family on a journey laying the dust». En: <http://www.britishmuseum.org/research/collection_online/collection_object_detaiIs.aspx?assetld=183706001\&objectld=1655763\&partld=1> (fecha de consulta: 25-02-19).

TONGIORGI TOMASI, Lucia (1995), «Tulipomania. Addenda», en GIUSTI, Maria Adriana \& TAGLIOLINI, Alessandro (eds.), I/ giardino delle muse. Arti e artificio nel barocco europeo, Edif-ir Edizioni Firenze, Firenze, pp. 79-96.

TOUS MELIÁ, Juan (2015), La medida del Teide: Descripcicón, erupciones y cartografía, Juan Tous Meliá, San Cristóbal de la Laguna.

VILLASEÑOR SEBASTIÁN, Fernando (2009), Iconografía marginal en Castilla (1454-1492), Instituto de Historia. Consejo Superior de Investigaciones Científicas, Madrid.

VON HUMBOLDT, Alexander (2011), Cosmos. Ensayo de una descripción física del mundo, Consejo Superior de Investigaciones Científicas, Madrid.

WALKER VADILLO, Mónica Ann (2013), «Los simios», Revista Digital de Iconografía Medieval, vol. V, n. 9, pp. 63-77.

WHEELOCK, Arthur K., Jr. «Potter, Paulus». En: <https://www.nga.gov/collection/artist-info.1797.html> (fecha de consulta: 25-02-19).

WUESTMAN, Gerdien (2006), «Berchem als etser: licht, meesterlijk en onnavolgbaar», en BIESBOER, Pieter, Nicolaes Berchem. In het licht van Italië, Ludion Uitgeverij, p. 124. 